\title{
Long-term resveratrol treatment prevents ovariectomy-induced osteopenia in rats without hyperplastic effects on the uterus
}

\author{
Haifeng Zhao ${ }^{1 *}$, Xuemin $\mathrm{Li}^{2}$, Na Li ${ }^{1}$, Tiantian $\mathrm{Liu}^{1}$, Juan $\mathrm{Liu}^{1}$, Ziwei $\mathrm{Li}^{1}$, Huihui Xiao ${ }^{1}$ and $\mathrm{Jinhui} \mathrm{Li}^{1}$ \\ ${ }^{1}$ Department of Nutrition and Food Hygiene, School of Public Health, Shanxi Medical University, No. 56, \\ Xinjian South Road, Taiyuan, Shanxi 030001, People's Republic of China \\ ${ }^{2}$ Center for Disease Control and Prevention, Shanxi Province, Taiyuan, Shanxi O30012, People's Republic of China \\ (Submitted 10 April 2013 - Final revision received 27 August 2013 - Accepted 28 August 2013 - First published online 30 September 2013)
}

\begin{abstract}
Resveratrol (Res), a polyphenol that is abundant in many medicinal plants and is a selective oestrogen receptor modulator, exhibits multiple biological activities. In the present study, we determined whether Res prevents oestrogen deficiency-induced osteopenia and whether Res administration decreases pathological changes in the endometrium and lumen of the uterus compared with oestradiol replacement therapy (ERT). A total of sixty 3-4-month-old female Wistar rats were randomly divided into a sham-operated group (Sham) and five ovariectomy (OVX) subgroups, i.e. OVX rats as a control group (OVX); OVX rats receiving oestradiol valerate (ERT, 0.8 mg/kg); and OVX rats receiving Res 20, 40 and $80 \mathrm{mg} / \mathrm{kg}$. Daily oral administration was initiated at week 2 after OVX for 12 weeks. A dose-response difference was observed in the effects of Res on bone mineral density (BMD) and trabecular microarchitecture. Only at the highest dose, bone loss was almost equivalent to that observed in the ERT group. The dose-response effects of Res on the biochemical parameters (alkaline phosphatase, IL-6, TNF- $\alpha$ and transforming growth factor- $\beta 1$ concentrations in the serum as well as urinary Ca and P excretion) and the expressions of receptor activator of nuclear factor $\kappa \mathrm{B}$ ligand (RANKL) and the RANKL:osteoprotegerin protein ratio in the femur were also observed. Furthermore, the thickening of the endometrium and the infiltration of lymphocytes were prevented in all the three Restreated groups compared with the ERT group. In conclusion, Res treatment not only improves BMD and trabecular microarchitecture but also does not affect the uterus and Res might be a potential remedy for the treatment of postmenopausal osteoporosis.
\end{abstract}

Key words: Resveratrol: Osteopenia: Ovariectomy: Bone mineral density: Receptor activator of nuclear factor $\boldsymbol{\kappa} B$ ligand/ osteoprotegerin

Postmenopausal osteoporosis (PMOP) is by far the most common cause of age-related bone loss and is recognised as one of the leading health care problems in the world ${ }^{(1)}$ PMOP is characterised by increased bone resorption, which in turn leads to increased bone fragility and fractures ${ }^{(2)}$. In addition, hip and spine fractures are associated with particularly high morbidity and mortality rates in POMP patients ${ }^{(3)}$.

It is well known that ovarian hormone deficiency is responsible for the development of PMOP. There is a strong association between POMP and sex, and the female:male ratio of hip fractures is greater than $2: 1$ in people aged above 50 years ${ }^{(4)}$.

The worldwide health and economic burden of osteoporosis is likely to increase in the future, as improvements in life expectancy will lead to an increase in the population of elderly people with a high risk of fractures. The population of people aged above 65 years has been predicted to increase from 58 million in 1995 to 108 million in 2040 in fifteen member states of the European Union. In particular, it has been estimated that the population aged above 80 years, in whom the incidence of osteoporotic fractures is highest, will increase from 8.9 million women and 4.5 million men in 1995 to 26.4 million women and $17 \cdot 4$ million men in $2050^{(4)}$. It has also been estimated that 10 million Americans aged above 50 years have osteoporosis and that a further 34 million are at a risk of the disease. An estimated 1.5 million fragility fractures occur every year. While most American women aged below 50 years have normal bone mineral density (BMD), 27\% are osteopenic and $70 \%$ are osteoporotic at the hip, lumbar spine or forearm by the age of 80 years ${ }^{(5)}$.

Modern therapy recommended for the treatment of PMOP includes supplementation with oestrogen and calcitonin, etc. However, the therapeutic management has several downsides,

Abbreviations: ALP, alkaline phosphatase; BMD, bone mineral density; BW, body weight; ERT, oestradiol replacement therapy; FGF, fibroblast growth factors; OPG, osteoprotegerin; OVX, ovariectomy; PMOP, postmenopausal osteoporosis; RANKL, receptor activator of nuclear factor $\kappa \mathrm{B}$ ligand; Res, resveratrol; Tb.Ar, trabecular area; Tb.N, trabecular number; Tb.Sp, trabecular separation; Tb.Th, trabecular thickness; TGF- $\beta 1$, transforming growth factor- $\beta 1$; TRAP, tartrate-resistant acid phosphatase.

*Corresponding author: H. Zhao, fax +86 3514135046 , email haifengzao75@163.com 
and available evidence suggests that the long-term use of oestradiol replacement therapy (ERT) may lead to serious side effects such as breast or uterus cancer ${ }^{(6,7-9)}$. Guidelines state that oestrogen is to be used for menopausal symptom relief and be given for the shortest duration possible ${ }^{(10)}$. Scientists throughout the world are looking for better alternative therapeutic management, especially from natural resources that can provide greater symptom relief with minimal risks, and preventive strategies of optimising early gains of bone mass are being preferred ${ }^{(11)}$.

Resveratrol (3,5,4'-trihydroxystilbene, Res), a non-flavonoid polyphenol that is abundant in grapes and a variety of medicinal plants, exhibits multiple biological activities ${ }^{(12,13)}$. It belongs to the group of phyto-oestrogens called selective oestrogen receptor modulators and exhibits a weak oestrogenic activity $^{(14)}$. In addition, Res has been shown to have significant antioxidant properties ${ }^{(15-17)}$. Furthermore, previous studies have reported that Res can enhance proliferation and osteoblast differentiation in human mesenchymal stem cells via ER-dependent extracellular-signal-regulated kinases 1/2 activation $^{(18)}$. He's study ${ }^{(19)}$ has indicated the preventive effect of Res on the receptor activator of nuclear factor $\kappa \mathrm{B}$ ligand (RANKL)-induced osteoclast differentiation of murine osteoclast progenitor RAW 264.7 cells through the inhibition of reactive oxygen species production. Other studies have reported that Res suppresses microcirculation levels in the osteal tissue ${ }^{(20)}$ and promotes osteogenesis in human mesenchymal stem cells ${ }^{(21)}$. Furthermore, Res can attenuate ovariectomy (OVX)-induced hypertension and bone loss in stroke-prone spontaneously hypertensive rats and regulate bone morphogenetic protein- $2^{(22,23)}$.

Based on the available information ${ }^{(24,25)}$, we presumed that Res would prevent bone loss in ovarian hormone deficiency. Therefore, the present study was designed to examine the extent to which Res prevents bone loss leading to osteopenia in OVX rats and the underlying mechanisms. Furthermore, the pathological change in the endometrium and lumen of the uterus of the Res-treated rats compared with that in the uterus of the ERT rats was investigated.

\section{Materials and methods \\ Resveratrol}

Res was obtained from Xi'an Helin Biological Engineering Company, Limited. Its purity was greater than $98 \%$ when checked by HPLC, and the analysis was carried out by Xi'an Helin Biological Engineering Company, Limited.

\section{Animals and treatments}

A total of sixty virgin adult (3-4 months old) female Wistar rats weighing 200-220g were used, and the present study was approved by the animal service of Shanxi Medical University. The rats were bred under conditions of controlled temperature $\left(22 \pm 0.5^{\circ} \mathrm{C}\right)$, humidity $(50 \pm 10 \%)$ and lighting (12 h light $-12 \mathrm{~h}$ dark cycle, light period began at 07.00 hours). All the rats were given free access to distilled water and fed standard rat chow. The animal care and experimental procedures were carried out in accordance with the Guidelines for Animal Experimentation of Shanxi Medical University, with the approval of the Institutional Animal Care and Use Committee.

The acclimatised rats were subjected to either bilateral laparotomy (Sham, $n$ 10) or bilateral OVX (OVX, $n$ 50). After recovery from surgery, the OVX rats were randomly divided into five groups: OVX rats as a control group (OVX, $n$ 10); OVX rats receiving oestradiol valerate (ERT, $n$ 10, $0.8 \mathrm{mg} / \mathrm{kg}$ ); OVX rats receiving Res at graded doses (Res $20 \mathrm{mg} / \mathrm{kg}, n$ 10; Res $40 \mathrm{mg} / \mathrm{kg}, n$ 10; and Res $80 \mathrm{mg} / \mathrm{kg}, n 10$ ). Based on the Human Rat Equivalent Dose Conversion Principle ${ }^{(26,27)}$, the experimental dose of oestradiol valerate used in the present study was equivalent to the corresponding clinical prescription dose for a $60 \mathrm{~kg}$ human subject. Res and oestradiol valerate were orally administered through a custom-made stomach tube for 12 weeks. During the experiment, the weight of the rats was measured once a week.

\section{Tissue preparation}

After Res treatment, rats in all the groups were subjected to an overnight fast, and blood samples were collected from the external jugular vein ${ }^{(28-30)}$. The blood samples were collected in microcentrifuge tubes and allowed to clot at room temperature. The blood samples were centrifuged ( $3000 \mathrm{rpm}$ for $5 \mathrm{~min}$ ), and then serum was separated and stored at $-80^{\circ} \mathrm{C}$ until the determination of alkaline phosphatase (ALP), tartrate-resistant acid phosphatase (TRAP), transforming growth factor- $\beta 1$ (TGF- $\beta 1$ ), fibroblast growth factor (FGF), IL- 6 and TNF- $\alpha$ concentrations. Both femurs of each rat were dissected for the measurements of BMD and morphological and physical parameters.

\section{Analysis of serum and urine chemistry}

An increase in urinary $\mathrm{Ca}$ excretion as well as a decrease in Ca absorption efficiency might lead to the reduction of BMD. $\mathrm{P}$ plays an important role in the process of bone metabolism, and it can promote the synthesis of bone matrix and the deposition of inorganic salts. In addition, ALP and TRAP are considered to be bone turnover markers ${ }^{(22)}$. Bone destruction and inflammation are closely associated ${ }^{(31)}$.

Serum Ca and serum P concentrations were measured by the ortho-cresol phthalein complexone method and the ammonium molybdate method using an autoanalyser, respectively ${ }^{(32)}$. Urinary Ca and urinary $\mathrm{P}$ concentrations were measured by the method used for the serum samples.

ALP and TRAP concentrations were measured using a commercial kit and a semi-autoanalyser (Jiancheng Institute of Biotechnology). In addition, TGF- $\beta 1$, FGF, IL- 6 and TNF- $\alpha$ concentrations were measured using an ELISA kit (Senxiong Biotech) according to the manufacturer's instructions. All assays were carried out in duplicate.

\section{Femur physical parameters}

Fresh isolated left femur was weighed using an electronic scale. Femoral length and external diameter were measured 


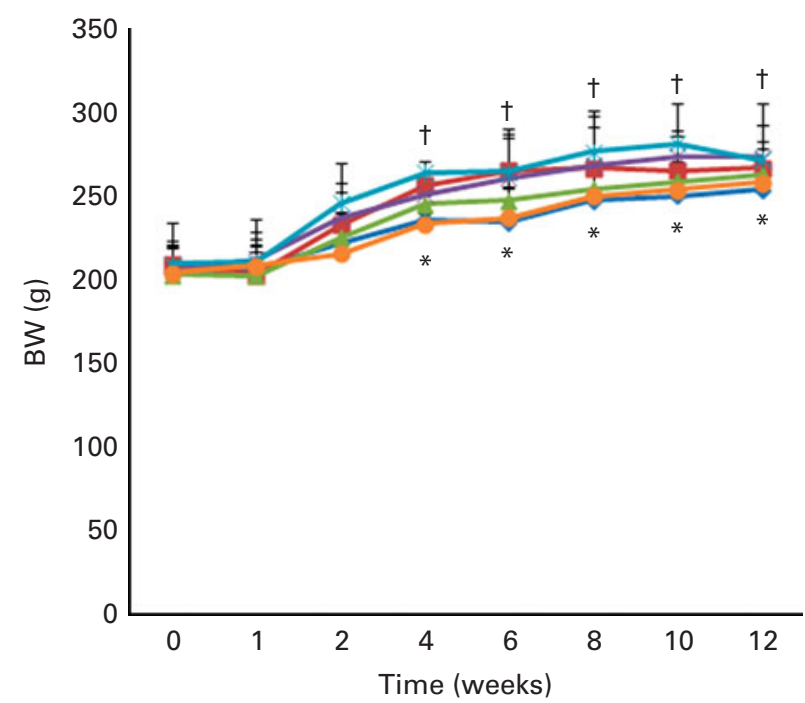

Fig. 1. Effect of resveratrol (Res) on body weight. The body weight (BW) of the rats was recorded weekly during the experimental period. Values are means, with standard deviations represented by vertical bars, and they were analysed by two-way ANOVA with repeated measures and the factors of group and time. All the six groups of rats had a similar initial mean BW ( $P>0.05$ among all the groups). However, during week 4 after surgery, the BW of the ovariectomy (OVX, - $)$ group was significantly higher than that of the Sham (-) group. The BW of the OVX group continued to increase significantly throughout the study period when compared with that of the Sham group. Oestradiol administration completely prevented the increase in BW associated with oestradiol deficiency and the BW levels returned to the levels observed in the Sham group 4 weeks after treatment. All the three doses of Res (Res $20 \mathrm{mg} / \mathrm{kg}\left({ }_{-}\right)$, Res $40 \mathrm{mg} / \mathrm{kg}(*)$ and Res $80 \mathrm{mg} / \mathrm{kg}\left({ }^{*}\right)$ groups) had no significant effects on BW (OVX and Res 20,40 and $80 \mathrm{mg} / \mathrm{kg}$ groups $v$. oestradiol replacement therapy (ERT, -- ) and Sham groups: $P<0.05$; Res 20, 40 and $80 \mathrm{mg} / \mathrm{kg}$ groups $v$. OVX group: $P>0.05$; ERT group $v$. Sham group: $P>0.05)$. ${ }^{*}$ Mean value was significantly different from that of the OVX group $(P<0.05)$. † Mean value was significantly different from that of the Sham group $(P<0.05)$. (A colour version of this figure can be found online at http://journals.cambridge.org/bjn).

using digital slide calipers. Femoral length was measured from the proximal tip of the head of the femur to the distal tip of the medial condyle. The external diameter of the femur was measured at the midshaft. The dry weight of bone can indirectly reflect the mineral content in the bone, so the femur was dried at $110^{\circ} \mathrm{C}$ for $12 \mathrm{~h}$, and the weight of the dried femur was determined after measuring the above-mentioned parameters ${ }^{(33)}$.

\section{Bone densitometry}

After removing the soft tissue, the right femur of each rat was subjected to densitometric (dual-energy X-ray absorptiometry technique) measurements of BMD. For the measurements, the bone was placed on its posterior surface in a thin-walled plastic container filled with $0.9 \% \mathrm{NaCl}$ and scanned using a Lunar Prodigy densitometer with a built-in small animal mode (GEMedical Systems). BMD was measured at the distal end of the femur (region $1 \mathrm{~cm}$ in length from the most distal point of the bone), femoral neck and femoral diaphysis (mid-diaphyseal region). The $\mathrm{CV}$ for the measurements (determined by thirty separate scans) was $<3 \%{ }^{(34)}$. All the measurements were taken by the same investigator.

\section{Bone morphology and histology}

Samples were obtained from the right distal femur of rats in each group and used as decalcified specimens for bone histomorphometric analysis. The femur samples were fixed in $10 \%$ phosphate-buffered formalin for $24 \mathrm{~h}$, dehydrated in a vacuum desiccator with graded ethanol, and then defatted in xylene and embedded in methyl methacrylate. Sections ( $4 \mu \mathrm{m}$ thick) were cut with a rotary microtome (Weswox Optik) and stained with haematoxylin-eosin for trabecular bone histomorphometric analysis ${ }^{(35)}$.

In the present study, the static measurements included the following parameters: the percentage of trabecular area (Tb.Ar); trabecular thickness (Tb.Th); trabecular number (Tb.N); trabecular separation (Tb.Sp).

\section{Determination of the expressions of IL-6, TNF- $\alpha$, osteoprotegerin and receptor activator of nuclear factor $\kappa B$ in the femur by immunohistochemistry}

To determine the expressions of IL- 6 , TNF- $\alpha$, osteoprotegerin (OPG) and RANKL in the femur, sections were deparaffinised using xylene and rehydrated using a graded series of alcohol concentrations. Endogenous peroxidase was quenched using $3 \%$ hydrogen peroxide for $10 \mathrm{~min}$. Non-specific binding of epitopes was blocked using 1:10 normal blocking serum. Slides were incubated at $4{ }^{\circ} \mathrm{C}$ overnight with a $1: 100$ dilution

Table 1. Effects of resveratrol (Res) on the femoral size and weight of ratsł

(Mean values and standard deviations)

\begin{tabular}{|c|c|c|c|c|c|c|c|c|c|}
\hline \multirow[b]{2}{*}{ Group } & \multirow[b]{2}{*}{$n$} & \multicolumn{2}{|c|}{$\begin{array}{c}\text { Femoral } \\
\text { length }(\mathrm{mm})\end{array}$} & \multicolumn{2}{|c|}{$\begin{array}{c}\text { Femoral } \\
\text { diameter }(\mathrm{mm})\end{array}$} & \multicolumn{2}{|c|}{ Wet weight (g) } & \multicolumn{2}{|c|}{ Dry weight (g) } \\
\hline & & Mean & SD & Mean & SD & Mean & SD & Mean & SD \\
\hline Sham & 7 & 34.20 & 1.09 & $3 \cdot 70$ & 0.45 & $0.600^{*}$ & 0.224 & $0.473^{\star}$ & 0.072 \\
\hline OVX & 7 & 32.60 & 0.89 & 4.00 & 0.01 & $0.420 \dagger$ & 0.084 & $0.337 \dagger$ & 0.049 \\
\hline Res $20 \mathrm{mg} / \mathrm{kg}$ & 7 & 33.20 & 2.39 & 4.00 & 0.01 & 0.500 & 0.122 & 0.372 & 0.106 \\
\hline Res $40 \mathrm{mg} / \mathrm{kg}$ & 7 & 32.40 & 1.67 & $3 \cdot 80$ & 0.45 & $0.580^{*}$ & 0.148 & 0.370 & 0.076 \\
\hline Res $80 \mathrm{mg} / \mathrm{kg}$ & 7 & 34.00 & 2.08 & $3 \cdot 86$ & 0.38 & $0.643^{*}$ & 0.151 & $0.406^{\star}$ & 0.074 \\
\hline ERT & 7 & 33.88 & 2.90 & $3 \cdot 81$ & 0.37 & $0.700^{\star *}$ & 0.093 & $0.458^{\star *}$ & 0.067 \\
\hline
\end{tabular}

OVX, ovariectomy; ERT, oestradiol replacement therapy.

Mean values were significantly different from those of the OVX group: ${ }^{*} P<0.05,{ }^{* \star} P<0.01$

$\dagger$ Mean values were significantly different from those of the Sham group $(P<0.05)$.

$\ddagger$ Wet weight, dry weight and femoral length and diameter were determined at the time of sampling of the left femur. 


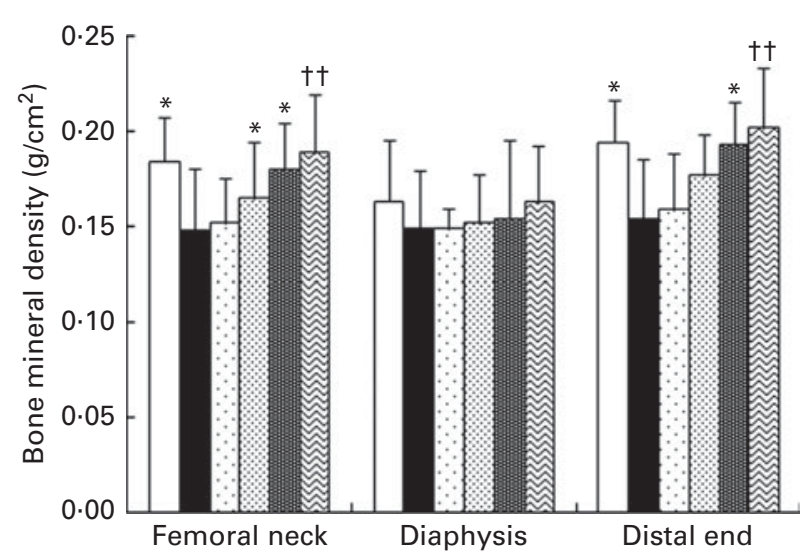

Fig. 2. Effect of resveratrol (Res) on bone mineral density. After Res treatment, the right femur of each rat was dissected and bone mineral density was measured by dual-energy $\mathrm{X}$-ray absorptiometry. Values are means, with standard deviations represented by vertical bars. ${ }^{*}$ Mean value was significantly different from that of the ovariectomy (OVX, $\square)$ group $(P<0.05)$. ††Mean value was significantly different from that of the OVX group $(P<0.01)$. , Sham control group; ㅁ, Res $20 \mathrm{mg} / \mathrm{kg}$ group; অ, Res $40 \mathrm{mg} / \mathrm{kg}$ group; $\mathbf{I}$, Res $80 \mathrm{mg} / \mathrm{kg}$ group; $\mathbf{\square}$, oestradiol replacement therapy group.

of rat IL-6, TNF- $\alpha$, OPG and RANKL primary antibodies (Boster Bio-Engineering Company, Limited). Sections were washed and incubated with biotinylated secondary antibodies (Boster Bio-Engineering Company, Limited) for $30 \mathrm{~min}$ followed by incubation with peroxidase substrate for $10 \mathrm{~min}$. The sections were washed and incubated in deionised water for $5 \mathrm{~min}$, counterstained with haematoxylin-eosin and observed under a light microscope. The expressions of these proteins were estimated by counting immunostained cells (percentage of cells), and the average score was used for the statistical analysis. Femurs of three rats were studied. For each rat, five slides and five fields in every slide were read, and all the slides were scored by two observers in a blinded fashion $^{(11)}$.

\section{Histological evaluation of the uterus}

The body of the uterus was cut right/just above the junction of the cervix. The uterus was stripped of fat and connective tissues. In addition to absolute weight, the relative weight (uterus weight/body weight (BW)) of the uterus of each rat was also calculated $(\mathrm{mg} / \mathrm{g})$.

Samples collected from the middle portions of both uterine horns were fixed in $10 \%$ neutral buffered formalin for $24 \mathrm{~h}$. Paraffin-embedded sections (6 mm; Leica SM2000R; Wyzner) were mounted on silanised slides, deparaffinised in xylene $(3 \times 5 \mathrm{~min})$, hydrated in a series of graded ethanol solutions, and washed in Tris-HCl buffer ( $\mathrm{pH} 7 \cdot 6$ ). The general appearance and the pathological changes in the endometrium and lumen of the uterus were observed using a light microscope.

\section{Statistical analysis}

All the data are expressed as means and standard deviations. Statistical analysis was carried out using one-way ANOVA, followed by the least significant difference (LSD) test (equal variances or homogeneity of variance assumed after variable transformation) or Dunnett's T3 (equal variances not assumed after variable justification) for post hoc testing between groups. Data were considered to be statistically significant
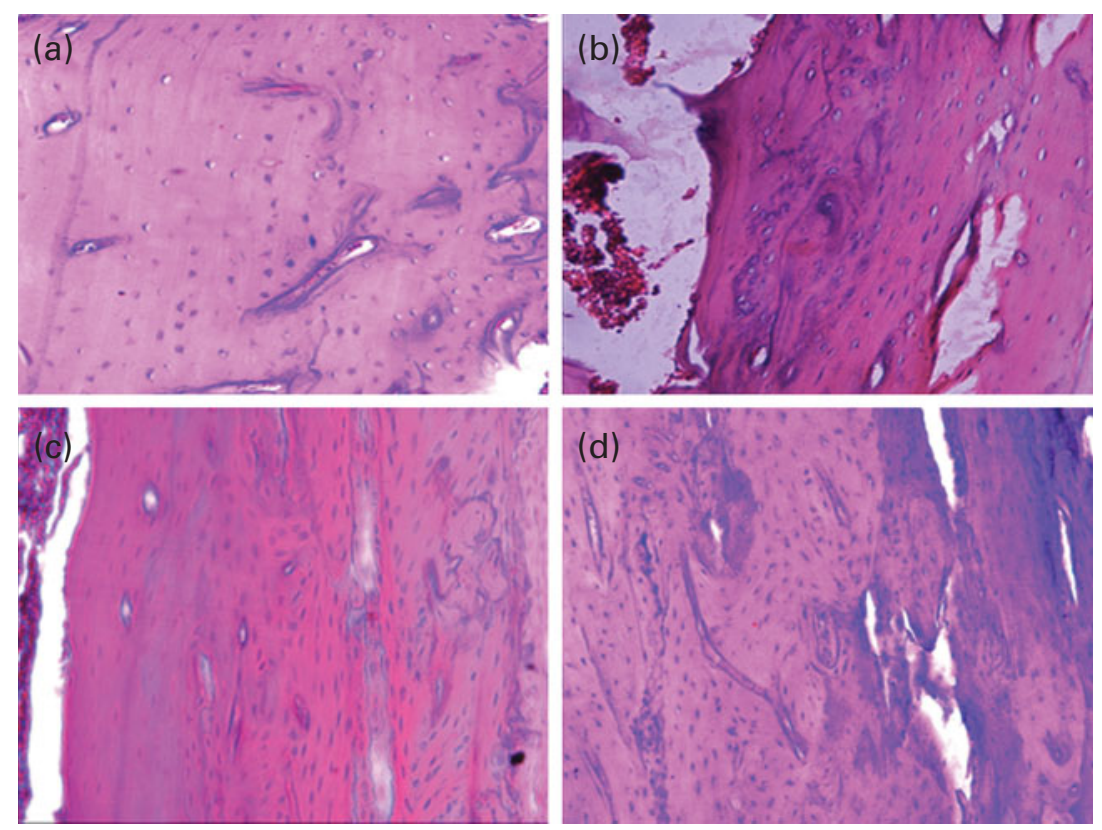

Fig. 3. Effect of resveratrol (Res) on bone architecture. After Res treatment, the right distal femur of each rat was dissected, and bone architecture was observed under a bright-field microscope after staining the sample with haematoxylin and eosin at 200x magnification. (a) Normal bone architecture in the Sham group; (b) altered bone architecture in the ovariectomy group; (c) partially recovered bone architecture in the Res $80 \mathrm{mg} / \mathrm{kg}$ group; (d) the bone architecture in oestradiol replacement therapy group. (A colour version of this figure can be found online at http://journals.cambridge.org/bjn). 
Table 2. Changes in the trabecular bone histomorphometric parameters of rats $\dagger$ (Mean values and standard deviations)

\begin{tabular}{|c|c|c|c|c|c|c|c|c|}
\hline \multirow[b]{2}{*}{ Group } & \multicolumn{2}{|c|}{ Tb.Ar (\%) } & \multicolumn{2}{|c|}{ Tb.Th $(\mu \mathrm{m})$} & \multicolumn{2}{|c|}{ Tb.Sp (mm) } & \multicolumn{2}{|c|}{ Tb.N (no. /mm) } \\
\hline & Mean & SD & Mean & SD & Mean & SD & Mean & SD \\
\hline Sham & $39 \cdot 37^{\star \star}$ & 3.24 & $69 \cdot 48^{* *}$ & 1.73 & $89 \cdot 72^{* *}$ & $10 \cdot 23$ & $7.42^{*}$ & 1.03 \\
\hline OVX & $19 \cdot 86$ & 4.12 & $43 \cdot 29$ & $2 \cdot 06$ & 179.06 & $9 \cdot 38$ & $5 \cdot 16$ & 0.68 \\
\hline Res $20 \mathrm{mg} / \mathrm{kg}$ & $22 \cdot 34$ & 3.08 & 42.96 & $3 \cdot 12$ & $167 \cdot 24$ & 8.28 & $5 \cdot 18$ & 0.74 \\
\hline Res $40 \mathrm{mg} / \mathrm{kg}$ & $32 \cdot 46^{\star}$ & $5 \cdot 26$ & $52 \cdot 36^{*}$ & $2 \cdot 14$ & $132 \cdot 44^{\star}$ & $10 \cdot 63$ & $6 \cdot 24^{\star}$ & $1 \cdot 12$ \\
\hline Res $80 \mathrm{mg} / \mathrm{kg}$ & $34.71^{*}$ & 3.08 & $58 \cdot 71^{*}$ & 1.24 & $117 \cdot 24^{\star *}$ & 9.54 & $6.43^{\star}$ & 0.86 \\
\hline ERT & $37.45^{\star *}$ & $2 \cdot 14$ & $63 \cdot 28^{* *}$ & 1.06 & $100 \cdot 38^{* *}$ & $10 \cdot 21$ & $7 \cdot 06^{\star}$ & 1.08 \\
\hline
\end{tabular}

Tb.Ar, trabecular area; Tb.Th, trabecular thickness; Tb.Sp, trabecular separation; Tb.N, trabecular number; OVX, ovariectomy; Res, resveratrol; ERT, oestradiol replacement therapy.

Mean values were significantly different from those of the OVX group; ${ }^{\star} P<0.05,{ }^{\star \star} P<0.01$.

†After Res treatment, samples were obtained from the right distal femur and Tb.Ar, Tb.Th, Tb.Sp and Tb.N were determined. Femurs of three rats were studied. For each rat, five slides and five fields in every slide were read, and all the slides were scored by two observers in a blinded fashion.

when a $P$ value $<0.05$ was achieved. All the tests were carried out using the SPSS 13.0 software.

\section{Results}

\section{Effect of resveratrol on body weight and food intake}

No deaths or obvious clinical signs (such as activity decrease, hair loss and diarrhoea) were observed in any of the groups throughout the experimental period. Daily food intake per rat did not differ among any of the groups: OVX: 21.47 (SD 1.19) g/d; Sham: 19.55 (sD 1.69) g/d; Res $20 \mathrm{mg} / \mathrm{kg}: 20.49$ (sD 3.23$) \mathrm{g} / \mathrm{d}$; Res $40 \mathrm{mg} / \mathrm{kg}: 20.77(\mathrm{SD} 1.72) \mathrm{g} / \mathrm{d}$; Res $80 \mathrm{mg} / \mathrm{kg}$ : 23.15 (SD 1.17) g/d; ERT 20.03 (SD 1.98) g/d.

BW was analysed using two-way ANOVA with repeated measures and the factors of group and time. The six groups of rats had a similar initial mean BW $(P>0.05$ among all the groups). However, during week 4 after surgery, the BW of the OVX group was significantly higher than that of the Sham group. The BW of the OVX group continued to increase significantly throughout the study period when compared with that of the Sham group. Oestradiol administration completely prevented the increase in BW associated with oestradiol deficiency, and the BW levels returned to levels observed in the Sham group 4 weeks after treatment. In the Res 20, 40 and $80 \mathrm{mg} / \mathrm{kg}$ groups, no significant effects of Res on BW were observed (OVX and Res 20, 40, $80 \mathrm{mg} / \mathrm{kg} v$. ERT and Sham: $P<0.05$; Res 20, $40,80 \mathrm{mg} / \mathrm{kg} v$. OVX: $P>0.05$; ERT $v$. Sham: $P>0.05$ ) (Fig. 1 ).

\section{Femoral length, diameter, wet weight and dry weight}

ANOVA indicated that the wet weight and dry weight of the femurs were significantly different among all the groups $(F(5,36)=2 \cdot 871, P<0 \cdot 05$, for wet weight; $F(5,36)=3 \cdot 124$, $P<0.05$, for dry weight). However, femoral length and diameter were not significantly different among all the groups $(F(5,36)=1.021, \quad P>0.05$, for femoral length; $F(5,36)=1.924, P>0.05$, for femoral diameter). In addition, the dry weights of the femurs in the Res $80 \mathrm{mg} / \mathrm{kg}$ group and the ERT group were significantly higher than those of the femurs in the OVX group (Table 1).

\section{Femoral bone mineral density}

The BMD of the neck and distal end of the femur in the Res 40 and $80 \mathrm{mg} / \mathrm{kg}$ groups and the ERT group was significantly

Table 3. Effects of resveratrol (Res) on the biochemical parameters of rats $\dagger$ (Mean values and standard deviations)

\begin{tabular}{|c|c|c|c|c|c|c|c|c|c|c|c|c|c|}
\hline \multirow[b]{2}{*}{ Group } & \multirow[b]{2}{*}{$n$} & \multicolumn{2}{|c|}{$\begin{array}{c}\text { Serum Ca } \\
(\mathrm{mmol} / \mathrm{l})\end{array}$} & \multicolumn{2}{|c|}{$\begin{array}{l}\text { Serum P } \\
(\mathrm{mmol} / \mathrm{l})\end{array}$} & \multicolumn{2}{|c|}{$\begin{array}{l}\text { Urinary } \mathrm{Ca} / \mathrm{Cr} \\
(\mathrm{mmol} / \mathrm{mmol})\end{array}$} & \multicolumn{2}{|c|}{$\begin{array}{l}\text { Urinary } \mathrm{P} / \mathrm{Cr} \\
(\mathrm{mmol} / \mathrm{mmol})\end{array}$} & \multicolumn{2}{|c|}{ ALP $(U / I) \ddagger$} & \multicolumn{2}{|c|}{ TRAP $(U / I) \S$} \\
\hline & & Mean & $\mathrm{SD}$ & Mean & SD & Mean & SD & Mean & SD & Mean & SD & Mean & SD \\
\hline Sham & 7 & $2 \cdot 27$ & 0.39 & $2 \cdot 46$ & 0.47 & $0 \cdot 21^{* *}$ & 0.03 & $4 \cdot 03^{\star *}$ & 0.72 & $141 \cdot 3^{\star \star}$ & 18.06 & $15 \cdot 04$ & 0.69 \\
\hline OVX & 7 & $2 \cdot 18$ & 0.42 & $2 \cdot 34$ & 0.52 & 0.43 & 0.04 & $5 \cdot 26$ & $1 \cdot 12$ & $290 \cdot 5$ & $17 \cdot 29$ & $17 \cdot 44$ & $6 \cdot 73$ \\
\hline Res $20 \mathrm{mg} / \mathrm{kg}$ & 7 & $2 \cdot 13$ & 0.22 & $2 \cdot 56$ & 0.41 & 0.41 & 0.05 & 5.08 & 0.87 & $289 \cdot 3$ & $17 \cdot 35$ & $15 \cdot 63$ & $5 \cdot 13$ \\
\hline Res $40 \mathrm{mg} / \mathrm{kg}$ & 7 & $2 \cdot 32$ & 0.8 & 2.53 & 0.26 & $0.34^{*}$ & 0.07 & $4 \cdot 64^{*}$ & 0.54 & $236 \cdot 0^{*}$ & $9 \cdot 38$ & $14 \cdot 13$ & $10 \cdot 89$ \\
\hline Res $80 \mathrm{mg} / \mathrm{kg}$ & 7 & $2 \cdot 26$ & 0.23 & 2.42 & 0.24 & $0.31^{*}$ & 0.04 & $4 \cdot 22^{\star *}$ & 0.63 & $231 \cdot 3^{*}$ & 11.47 & $12 \cdot 19$ & $4 \cdot 13$ \\
\hline ERT & 7 & 2.02 & 0.17 & $2 \cdot 37$ & 0.19 & $0 \cdot 26^{\star \star}$ & 0.06 & $4 \cdot 28^{\star \star}$ & 0.75 & $226 \cdot 4^{\star \star}$ & $12 \cdot 49$ & $13 \cdot 8$ & 3.66 \\
\hline
\end{tabular}

$\mathrm{Cr}$, creatinine; ALP, alkaline phosphatase; TRAP, tartrate-resistant acid phosphatase; OVX, ovariectomy; ERT, oestradiol replacement therapy.

Mean values were significantly different from those of the OVX group: ${ }^{\star} P<0.05,{ }^{\star \star} P<0.01$.

† After Res treatment, blood and urine samples were collected and the biochemical parameters were measured.

$\ddagger 1 \mu \mathrm{ALP}=1 \mathrm{mg}$ phenol produced when $100 \mathrm{ml}$ serum interacts with substrate for $15 \mu \mathrm{m}$ at $37^{\circ} \mathrm{C}$.

$\S 1 \mu$ TRAP $=1 \mathrm{mg}$ phenol produced when 1 litre serum interacts with substrate for $1 \mathrm{~min}$ at $37^{\circ} \mathrm{C}$. 
Table 4. Concentrations of IL-6, TNF- $\alpha$, transforming growth factor- $\beta 1$ (TGF- $\beta 1$ ) and fibroblast growth factors (FGF) in the serum $\ddagger$

(Mean values and standard deviations)

\begin{tabular}{|c|c|c|c|c|c|c|c|c|c|}
\hline \multirow[b]{2}{*}{ Group } & \multirow[b]{2}{*}{$n$} & \multicolumn{2}{|c|}{ IL-6 (pg/ml) } & \multicolumn{2}{|c|}{ TNF- $\alpha$ (ng/ml) } & \multicolumn{2}{|c|}{ TGF- $\beta 1$ (ng/ml) } & \multicolumn{2}{|c|}{$\mathrm{FGF}(\mathrm{pg} / \mathrm{ml})$} \\
\hline & & Mean & SD & Mean & SD & Mean & SD & Mean & SD \\
\hline Sham & 7 & $18 \cdot 68^{* \star}$ & $1 \cdot 20$ & $5 \cdot 27^{\star \star}$ & 1.05 & $75 \cdot 15^{\star}$ & $7 \cdot 66$ & $227 \cdot 32^{\star}$ & 21.91 \\
\hline OVX & 7 & $23 \cdot 70+\dagger$ & 1.42 & $8 \cdot 29+\dagger$ & 0.71 & $47.49 \dagger$ & $2 \cdot 67$ & $182.82 \dagger$ & $12 \cdot 33$ \\
\hline Res $20 \mathrm{mg} / \mathrm{kg}$ & 7 & $18.09^{\star *} \dagger$ & 1.59 & $6 \cdot 57^{* *}$ & 0.25 & $52.46^{\star} \dagger$ & 4.45 & $185 \cdot 37 \dagger$ & 8.62 \\
\hline Res $40 \mathrm{mg} / \mathrm{kg}$ & 7 & $21 \cdot 23^{*}+\dagger$ & 1.38 & $5 \cdot 98^{\star *}$ & 0.69 & $59.99^{*} \dagger$ & 7.57 & $183 \cdot 26 \dagger$ & $15 \cdot 24$ \\
\hline Res $80 \mathrm{mg} / \mathrm{kg}$ & 7 & $21.93^{*}+\dagger$ & 1.23 & $7 \cdot 11^{*}+\dagger$ & 0.73 & $66 \cdot 23^{*} \dagger$ & $6 \cdot 94$ & $196 \cdot 11 \dagger$ & 10.08 \\
\hline ERT & 7 & $16 \cdot 12^{\star \star}+\dagger$ & $2 \cdot 31$ & $5 \cdot 81^{\star \star}$ & 1.00 & $75 \cdot 95^{\star}$ & $7 \cdot 66$ & $221 \cdot 29^{*}$ & 9.95 \\
\hline
\end{tabular}

OVX, ovariectomy; Res, resveratrol; ERT, oestradiol replacement therapy.

Mean values were significantly different from those of the OVX group: ${ }^{*} P<0.05,{ }^{\star \star} P<0.01$.

Mean values were significantly different from those of the Sham group: $+P<0.05,+\dagger P<0.01$

$\ddagger$ After Res treatment, serum was separated from the blood samples collected from the rats. The concentrations of IL-6, TNF- $\alpha$, TGF- $\beta 1$ and FGF in the serum were determined.

higher than that in the OVX group, with no significant changes being observed in the femoral diaphysis. No statistical significance was observed for BMD between the Res $20 \mathrm{mg} / \mathrm{kg}$ group and the OVX group (Fig. 2)

\section{Effect of resveratrol on bone morphology and histology}

The histology of the femurs of the Sham rats (demineralised with EDTA and stained with haematoxylin and eosin) showed normal bone microarchitecture, when compared with that of the femurs of the OVX rats, where pathological alterations were observed. However, restoration of bone microarchitecture was observed in the Res $80 \mathrm{mg} / \mathrm{kg}$-treated rats, when compared with the OVX rats. The ERT rats also exhibited restoration (Fig. 3).

The histomorphometric quantitative changes of the trabecular bone mass and bone architecture in the sections of the right distal femur are summarised in Table 2. The OVX group exhibited a remarkable decrease in $\mathrm{Tb} . \mathrm{Ar}$, Tb.Th and Tb.N ( $P<0.05$ for Tb.N; $P<0.01$ for Tb.Th and Tb.Ar) and an increase in Tb.Sp $(P<0.01)$ compared with the Sham group. Res administration partially reversed these changes (Res $40 \mathrm{mg} / \mathrm{kg} v$. OVX: $P<0.05 ;$ Res $80 \mathrm{mg} / \mathrm{kg} v$. OVX: $P<0.05$ for Tb.Sp). Furthermore, in the ERT group, a better
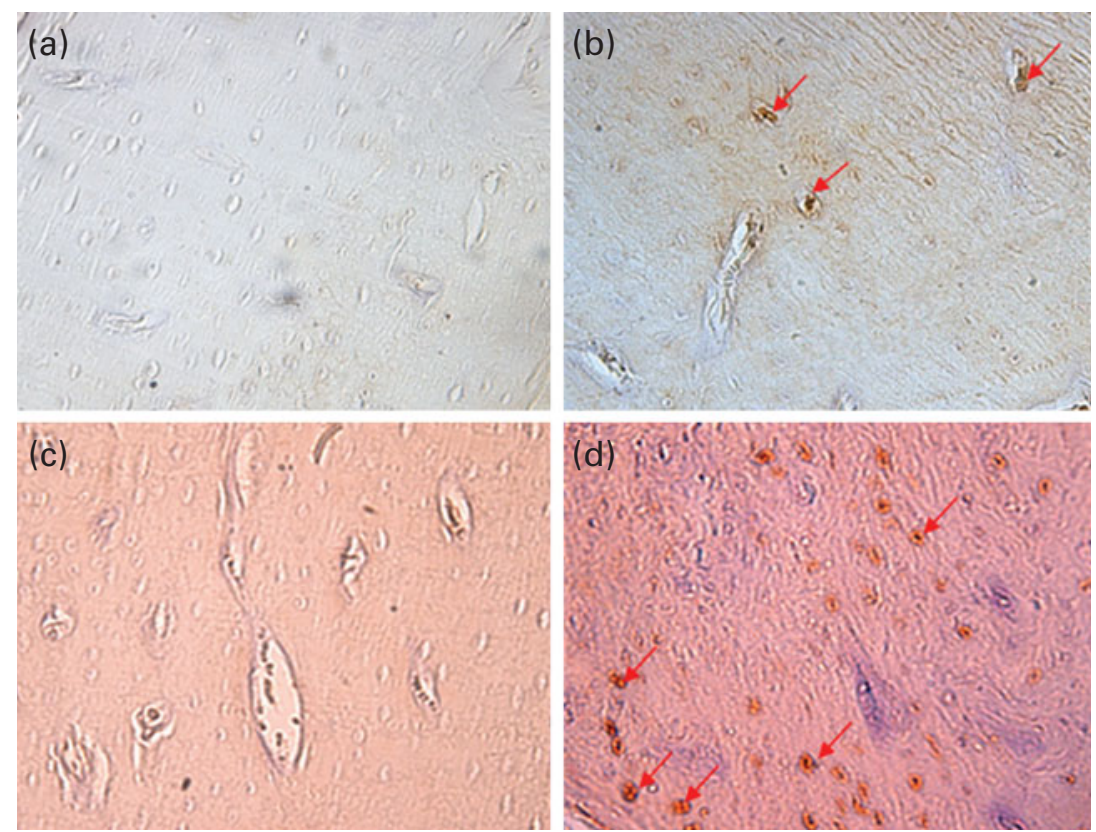

Fig. 4. Effect of resveratrol on the expressions of IL-6 and TNF- $\alpha$. After resveratrol treatment, femur samples were collected and the expressions of IL- 6 and TNF- $\alpha$ were analysed by immunohistochemical methods. (a, b) Representative photomicrographs of femur sections showing IL- 6 expression in the different groups ((a) the Sham group and (b) the OVX group). Images were acquired at 200x magnification. Arrows indicate IL-6-positive cells. (c, d) Representative photomicrographs of femur sections showing TNF- $\alpha$ expression in the different groups ((c) the Sham group and (d) the OVX group). Images were acquired at $200 \times$ magnification. Arrows indicate TNF- $\alpha$-positive cells. (A colour version of this figure can be found online at http://journals.cambridge.org/bjn). 

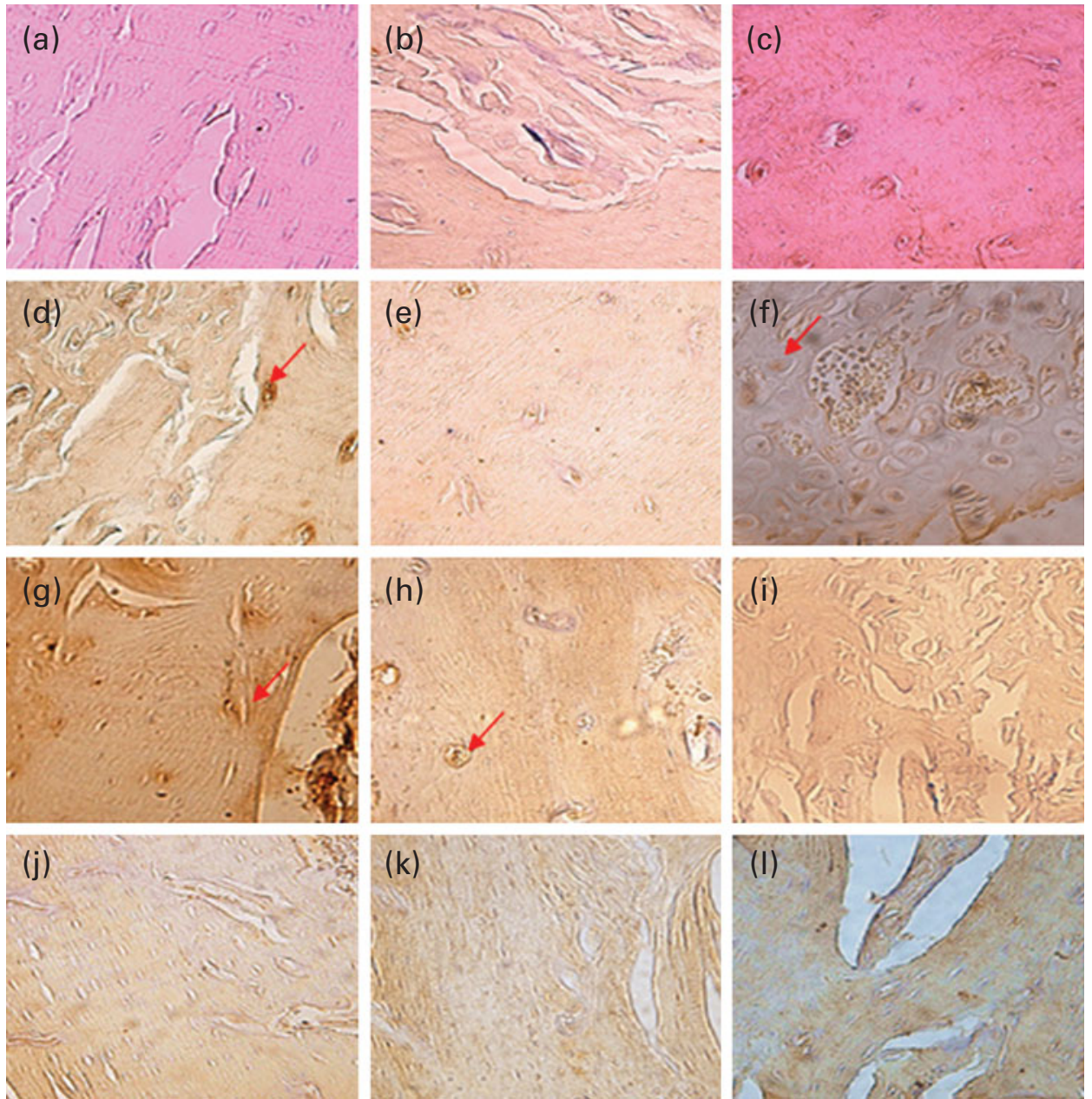

Fig. 5. Effect of resveratrol (Res) on the expressions of osteoprotegerin (OPG) and receptor activator of nuclear factor $\mathrm{kB}$ ligand (RANKL). After treatment, femur samples were collected and the expressions of OPG and RANKL were analysed by immunohistochemical methods. ((a)-(f)) Representative photomicrographs of femur sections showing OPG expression in the different groups : (a) the ovariectomy (OVX) group; (b-d) the Res 20, 40 and $80 \mathrm{mg} / \mathrm{kg}$ groups; (e) the oestradiol replacement therapy (ERT) group; (f) the Sham group. ((g)-(l)) Representative photomicrographs of femur sections showing RANKL expression: (g) the OVX group; ((h)-(j)) the Res 20, 40 and $80 \mathrm{mg} / \mathrm{kg}$ groups; (k) the ERT group; (I) the Sham group. Images were acquired at 200x magnification. Arrows indicate the OPG- or RANKL-positive cells. (A colour version of this figure can be found online at http://journals.cambridge.org/bjn).

Table 5. Effects of resveratrol (Res) on the expressions of IL-6, TNF- $\alpha$, osteoprotegerin (OPG) and receptor activator of nuclear factor $\kappa B$ ligand (RANKL) in the femurf

(Mean values and standard deviations)

\begin{tabular}{|c|c|c|c|c|c|c|c|c|}
\hline \multirow[b]{2}{*}{ Groups } & \multicolumn{2}{|c|}{ IL-6 (\%) } & \multicolumn{2}{|c|}{ TNF- $\alpha(\%)$} & \multicolumn{2}{|c|}{ OPG (\%) } & \multicolumn{2}{|c|}{ RANKL (\%) } \\
\hline & Mean & SD & Mean & SD & Mean & SD & Mean & SD \\
\hline Sham & $0.50^{\star \star}$ & 0.58 & $1 \cdot 75^{\star \star}$ & 0.50 & $16 \cdot 8^{*} \dagger$ & 1.92 & $9 \cdot 8^{*}$ & 1.64 \\
\hline ovX & $5 \cdot 75+\dagger$ & 0.50 & $25 \cdot 50 \dagger \dagger$ & 3.32 & $2.6 \dagger$ & 0.55 & $20 \cdot 2 \dagger$ & $2 \cdot 86$ \\
\hline Res $20 \mathrm{mg} / \mathrm{kg}$ & $2 \cdot 00^{\star \star} \dagger$ & 0.82 & $12 \cdot 50^{\star \star}+\dagger$ & 2.65 & $5 \cdot 8^{*} \dagger$ & 0.84 & $12 \cdot 2^{*} \dagger$ & 1.64 \\
\hline Res $40 \mathrm{mg} / \mathrm{kg}$ & $1.75^{\star \star} \dagger$ & 0.96 & $6 \cdot 25^{\star \star} \dagger$ & $2 \cdot 50$ & $11 \cdot 6^{*}$ & $1 \cdot 14$ & $8 \cdot 0^{*}$ & 1.00 \\
\hline Res $80 \mathrm{mg} / \mathrm{kg}$ & $2 \cdot 00^{* \star} \dagger$ & 0.82 & $4.75^{\star \star} \dagger$ & $2 \cdot 22$ & $16 \cdot 0^{*} \dagger$ & 1.87 & $7 \cdot 4^{\star}$ & $1 \cdot 14$ \\
\hline ERT & $1 \cdot 25^{\star \star} \dagger$ & 0.50 & $2 \cdot 00^{\star \star}$ & 0.82 & $12 \cdot 4^{*}$ & $3 \cdot 36$ & $6 \cdot 6^{*} \dagger$ & 0.55 \\
\hline
\end{tabular}

OVX, ovariectomy; ERT, oestradiol replacement therapy.

Mean values were significantly different from those of the OVX group: ${ }^{\star} P<0.05$, ${ }^{\star \star} P<0.01$.

Mean values were significantly different from those of the Sham group: $+P<0.05,++P<0.01$.

$\ddagger$ After Res treatment, femur samples were collected and the expressions of IL- 6 and TNF- $\alpha$ were analysed by immunohistochemical methods. Femurs of three rats were studied. The expression of these proteins was estimated by counting immunostained cells (percentage of cells), and the average score was used for the statistical analysis. For each rat, five slides and five fields in every slide were read, and all the slides were scored by two observers in a blinded fashion. 
efficacy for the prevention of the decrease in Tb.Ar, Tb.Th and Tb.N and the increase in Tb.Sp was observed when compared with the Res groups (ERT $v$. OVX: $P<0.01$ for all the indices).

\section{Serum and urine chemistry}

There were no significant differences in serum $\mathrm{Ca}$, serum $\mathrm{P}$ and TRAP concentrations among all the groups $(F(5,36)=0.434$, $P>0.05$, for serum Ca; $F(5,36)=0.762, P>0.05$, for serum $\mathrm{P}$; $F(5,36)=1 \cdot 561, P>0 \cdot 05$, for TRAP), while urinary Ca, urinary $\mathrm{P}$ and ALP concentrations in the OVX group were significantly increased compared with those in the Sham group $(P<0.01$ for both). In addition, Res 40 and $80 \mathrm{mg} / \mathrm{kg}$ administration significantly attenuated the increase in urinary $\mathrm{Ca}$, urinary $\mathrm{P}$ and ALP concentrations in the OVX group $(P<0.05$ or 0.01$)$ (Table 3).

\section{IL-6, TNF- $\alpha$, transforming growth factor- $\beta 1$ and fibroblast growth factor concentrations in the serum} determined by ELISA

The concentrations of IL- 6 and TNF- $\alpha$ were significantly different among the groups $(F(5,36)=19 \cdot 24, P<0 \cdot 01$, for IL-6; $F(5,36)=11 \cdot 40, P<0 \cdot 01$, for TNF- $\alpha$ ). The concentrations of IL- 6 in the ERT group and the Res 20 and $40 \mathrm{mg} / \mathrm{kg}$ groups were significantly decreased compared with those in the OVX rats (ERT and Res $20 \mathrm{mg} / \mathrm{kg} v$. OVX: $P<0.01$; Res 40 and $80 \mathrm{mg} / \mathrm{kg} v$. OVX: $P<0.05)$. However, the concentrations of IL- 6 and TNF- $\alpha$ in the Res 40 and $80 \mathrm{mg} / \mathrm{kg}$ groups were higher than those in the ERT group. The concentrations of TNF- $\alpha$ exhibited the same trend. The three Res dosages increased TGF- $\beta 1$ concentrations, but exhibited no effect on FGF concentrations in the serum (Table 4).

\section{IL-6, TNF- $\alpha$, osteoprotegerin and receptor activator of}

nuclear factor $\kappa B$ ligand expressions in the femur

determined by immunohistochemical analysis

Immunohistochemical analysis indicated that the expressions of IL-6, TNF- $\alpha$ and RANKL were significantly decreased in the Sham, the ERT and the three Res-treated rats compared with those in the OVX rats. However, the expression of OPG was increased in the Sham, the ERT and the three Res-treated rats compared with that in the OVX rats (Figs. 4 and 5). The quantitative analysis results are given in Table 5.

\section{Examination of uterus weight and histopathology}

Uterus weight and uterine index. Significant atrophy of uterine tissue was observed in the OVX group compared with the Sham group, indicating the success of OVX, and oestradiol administration significantly increased uterus weight compared with OVX $(F(5,36)=65.86, P<0.001$, for uterus weight; $F(5,36)=88.65, \quad P<0.001$, for uterine index), whereas Res did not exert any uterotrophic effect in the Res 20, 40 and $80 \mathrm{mg} / \mathrm{kg}$ groups (Table 6).
Table 6. Uterus weight and uterine index at the end of the treatment periodł

(Mean values and standard deviations)

\begin{tabular}{|c|c|c|c|c|}
\hline \multirow[b]{2}{*}{ Groups } & \multicolumn{2}{|c|}{ Uterus weight (g) } & \multicolumn{2}{|c|}{$\begin{array}{l}\text { Uterine index } \\
\quad(\mathrm{mg} / \mathrm{g})\end{array}$} \\
\hline & Mean & SD & Mean & SD \\
\hline Sham & $0.37^{\star \star}$ & 0.080 & $1.45^{\star \star}$ & 0.26 \\
\hline OVX & 0.096†† & 0.023 & $0.36 \dagger \dagger$ & 0.08 \\
\hline Res $20 \mathrm{mg} / \mathrm{kg}$ & $0.086+\dagger$ & 0.015 & $0.33+t$ & 0.06 \\
\hline Res $40 \mathrm{mg} / \mathrm{kg}$ & $0.084 \uparrow \dagger$ & 0.014 & $0.31 \dagger \dagger$ & 0.05 \\
\hline Res $80 \mathrm{mg} / \mathrm{kg}$ & $0.091+\dagger$ & 0.015 & $0.33+\dagger$ & 0.04 \\
\hline ERT & $0.222^{\star \star} \dagger$ & 0.046 & $0 \cdot 86^{\star \star}$ & 0.16 \\
\hline
\end{tabular}

OVX, ovariectomy; Res, resveratrol; ERT, oestradiol replacement therapy.

${ }^{* *}$ Mean values were significantly different from those of the OVX group $(P<0.01)$.

Mean values were significantly different from those of the Sham group: $\dagger P<0.05$, $\dagger+P<0.01$.

‡Uterus samples were collected after killing the rats. The absolute weight and the relative weight (uterus weight/body weight) were determined.

Histological examination of the uterus. Qualitative analyses were carried out on the general appearance of the uterus and on the endometrium and lumen. In the OVX group, the blue-stained connective tissue and its fibrous structure were not detected, and the lumen periphery was fragmented (Fig. 6(a) and (e)). In the ERT group, oedema was observed in the endometrium, and an abnormal increase in the uterine diameter was detected (Fig. 6(b) and (f)). In the Res $80 \mathrm{mg} / \mathrm{kg}$ group, a healthy epithelial layer was observed; however, the increase in diameter was substantially less than that in the ERT group, and the infiltration of lymphocytes in the Res $80 \mathrm{mg} / \mathrm{kg}$ group was less than that in the ERT group, implying a reduced immune reaction against ERT (Fig. 6(c) and $(\mathrm{g})$ ). In the Sham group, blue-stained healthy connective tissue was easily detected, and the lumen periphery was intact (Fig. 6(d) and (h)).

\section{Discussion}

PMOP is an oestrogen-deficient state characterised by bone fragility, as the balance between bone resorption and bone formation shifts towards increased levels of bone resorption. The OVX rat has been widely used as a model for the evaluation of potential treatments for PMOP due to its similarities with humans with regard to bone loss. In the present study, we assessed the ability of Res to prevent bone loss in OVX rats and the underlying mechanisms. Oestradiol was included in the study as a reference compound to study the effect of oestrogen on bone modelling and remodelling.

The study results indicate that Res treatment may significantly prevent oestrogen deficiency-induced BW gain without affecting the weight of the uterus in the OVX rat model. The results also indicate that treatment with Res or oestradiol valerate for 12 weeks can prevent the increased rates of urinary $\mathrm{Ca}$ and urinary $\mathrm{P}$ excretion induced by OVX, suggesting that the rate of bone turnover is downregulated by Res. 

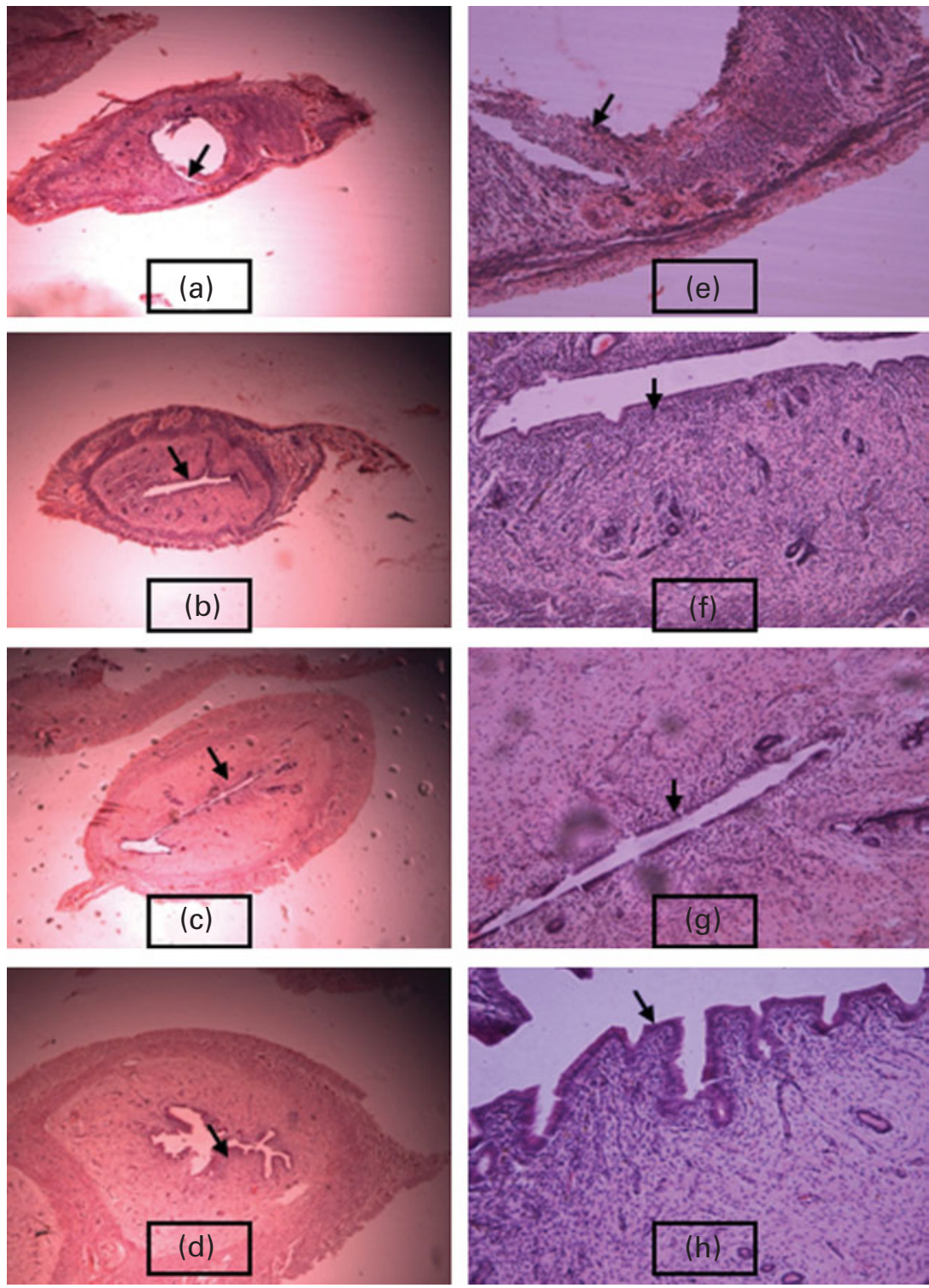

Fig. 6. Effect of resveratrol on the uterus. After killing the rats, samples from the middle portions of both uterine horns were collected and a histological examination of the samples was carried out. The samples were studied at $40 \times$ magnification (a-d) and 200x magnification (e-h). The endometrium was destructed and the lumen periphery was not intact in the ovariectomy (OVX) group (a, e); the destruction of the endometrium in the Res 20,40 and $80 \mathrm{mg} / \mathrm{kg}$ groups was much less than that in the OVX group and a healthy epithelial layer was observed. In addition, the increase in the uterine diameter was much less than that in the oestradiol replacement therapy (ERT) group (b, f); a healthy endometrium and an intact lumen periphery were observed, and oedema in the endometrium and an abnormal increase in the uterine diameter were also observed in the ERT group (c, g); healthy connective tissue and intact endometrium and lumen periphery were observed in the Sham control group $(\mathrm{d}, \mathrm{h}$ ). (A colour version of this figure can be found online at http://journals.cambridge.org/bjn).

Although ALP is a non-specific isoenzyme, it is accepted as a phenotype marker for bone formation and resorption ${ }^{(11)}$. In the present study, the increase in ALP concentrations was attenuated in the Res-treated groups ( $P<0.05$ or 0.01 ) (Table 3 ). The results demonstrate the potential protective action of Res due to increased bone formation with reduction of bone resorption.

The regulation of osteoblast differentiation and bone mineral formation is complex and involves a variety of factors. The most investigated and stable isoform is TGF- $\beta 1$, which acts at many stages ranging from the osteoblast precursor maturation to the mature osteoblast and matrix formation stage ${ }^{(36-38)}$. In bone, TGF- $\beta 1$ is secreted and stored in the synthesised mineral matrix and is subsequently released upon resorption by osteoclasts. In addition, some evidence indicates that FGF play important roles in the control of bone formation $^{(39,40)}$. In the present study, Res administration attenuated the decrease in TGF- $\beta 1$ concentrations observed in OVX rats. However, the effect of Res on FGF concentrations was less obvious.

OVX led to a significant decrease in BMD due to an increase in bone turnover in the OVX rats compared with the Sham rats. In the present study, Res administration prevented the 
OVX-induced decrease of BMD in the proximal tibia and femoral neck in the Res 40 and $80 \mathrm{mg} / \mathrm{kg}$ groups. The results indicate that Res administration can attenuate the decrease in BMD usually observed after OVX. However, the BMD value for the midshaft did not differ among all the groups. The midshaft region is dominated by cortical bone, while the distal metaphysis is mainly cancellous bone. At skeletal sites containing cancellous bone, change in BMD is more likely to be caused by OVX. Skeletal sites containing mainly cortical bone have been shown to be not significantly altered by oestrogen deficiency in rodents ${ }^{(41)}$.

The trabecular bone structure, the indices of which are good predictors of bone mass and bone strength, is more susceptible to bone loss due to OVX than the BMD. The histopathological analysis results indicate the preventive effect of Res on OVX-induced trabecular bone loss and microarchitecture deterioration. As expected, OVX significantly reduced the values of trabecular Tb.Ar, Tb.Th and Tb.N while increasing the value of Tb.Sp. Treatment with Res 40 and $80 \mathrm{mg} / \mathrm{kg}$ significantly inhibited these changes.

TNF- $\alpha$ and IL- 6 stimulate differentiation independently or in a synergistic fashion in osteoclasts and their precursors. Res treatment may positively affect bone by suppressing the release of pro-inflammatory cytokines from bone cells, the concentrations of which are often elevated after OVX. These cytokines also regulate the production of both receptor activator of NF- $\mathrm{kB}$ ligand (RANKL) in osteoblasts and OPG. The activated RANKL interacts with RANK present on the osteoclasts for bone resorption ${ }^{(42)}$. OPG is a novel anti-resorptive agent and a soluble secreted protein of the TNF receptor family that functions as a decoy receptor for RANKL. Therefore, the inhibition of the RANK/RANKL pathway inhibits osteoclast formation, differentiation and activation and bone resorption $^{(43-45)}$. To examine this hypothesis, we measured the concentrations of TNF- $\alpha$, IL-6, RANKL and OPG in the serum and in the femur. In the present study, Res administration prevented the increase in IL- 6 and TNF- $\alpha$ concentrations as well as the decrease in TGF- $\beta 1$ concentrations in OVX rats. In addition, the higher doses of Res ( 40 and $80 \mathrm{mg} / \mathrm{kg}$ ) exhibiting anti-osteoporosis activity involving osteoclasts may inhibit bone resorption (similar to OPG) by promoting the binding of RANKL to RANK to decrease osteoclastic activity.

Furthermore, the pathological changes in the endometrium and lumen of the uterus of the Res-treated rats compared with those in the uterus of the ERT rats were also investigated. A histological pattern of significant thickening of the endometrium was observed in the ERT group. However, none of the three Res-treated groups demonstrated any significant increase in the thickness of the endometrium compared with the ERT group. In addition, there were also less lymphocyte activities in the uterus of the three Res-treated groups compared with the ERT group. The reduced cell proliferation in the three Res-treated groups indicates that oestrogen antagonism of ERT's adverse effects in the uterus might be possible.

In conclusion, the present study demonstrates that daily oral administration of Res over a 12-week period in adult female OVX rats can prevent the oestrogen deficiency-induced bone loss without effects on the uterus. Therefore, Res might be a potential candidate for the treatment of PMOP.

\section{Acknowledgements}

The present study was supported by the National Natural Science Foundation of China (no. 81001245), Scientific and Technologial Innovation Programs of Higher Education Institutions in Shanxi of China (no. 2010009), and China Postdoctoral Science Foundation Grant (no. 2012M510778). All the funders contributed to the study design and conduct of the study.

The authors' contribution are as follows: H. Z. was responsible for the study concept, was in charge of the whole trial and wrote the manuscript; X. L., N. L., T. L., J. L., Z. L., H. X. and J. L. assisted in the animal trials and chemical analyses.

None of the authors has any conflicts of interest to declare.

\section{References}

1. Devareddy L, Hooshmand S, Collins JK, et al. (2008) Blueberry prevents bone loss in ovariectomized rat model of postmenopausal osteoporosis. J Nutr Biochem 19, 694-699.

2. Alexander JM, Bab I, Fish S, et al. (2001) Human parathyroid hormone $1-34$ reverses bone loss in ovariectomized mice. J Bone Miner Res 16, 1665-1673.

3. Doherty DA, Sanders KM, Kotowicz MA, et al. (2001) Lifetime and five-year age-specific risks of first and subsequent osteoporotic fractures in postmenopausal women. Osteoporos Int 12, 16-23.

4. Curran D, Maravic M, Kiefer P, et al. (2010) Epidemiology of osteoporosis-related fractures in France: a literature review. Joint Bone Spine 77, 546-551.

5. Holroyd C, Cooper C \& Dennison E (2008) Epidemiology of osteoporosis. Best Pract Res Clin Endocrinol Metab 22, 671-685.

6. Beral V, Reeves G, Bull D, et al. (2011) Breast cancer risk in relation to the interval between menopause and starting hormone therapy. J Natl Cancer Inst 103, 296-305.

7. Chlebowski RT, Anderson G, Manson JE, et al. (2010) Estrogen alone in postmenopausal women and breast cancer detection by means of mammography and breast biopsy. J Clin Oncol 28, 2690-2697.

8. Harman SM, Vittinghoff E, Brinton EA, et al. (2011) Timing and duration of menopausal hormone treatment may affect cardiovascular outcomes. Am J Med 124, 199-205.

9. Zhao M, Liu J, Zhang X, et al. (2009) 3D QSAR of novel estrogen-RGD peptide conjugates: getting insight into structural dependence of anti-osteoporosis activity and side effect of estrogen in ERT. Bioorg Med Chem 17, 3680-3689.

10. Grady D \& Sawaya GF (2005) Discontinuation of postmenopausal hormone therapy. Am J Med 118, Suppl. 12B, $163-165$.

11. Cheng M, Wang Q, Fan Y, et al. (2011) A traditional Chinese herbal preparation, Er-Zhi-Wan, prevent ovariectomyinduced osteoporosis in rats. J Ethnopharmacol 138 $279-285$.

12. de la Lastra CA \& Villegas I (2005) Resveratrol as an antiinflammatory and anti-aging agent: mechanisms and clinical implications. Mol Nutr Food Res 49, 405-430.

13. Delmas D, Jannin B \& Latruffe N (2005) Resveratrol: preventing properties against vascular alterations and ageing. Mol Nutr Food Res 49, 377-395. 
14. Tasci A, Bilgili H, Altunay H, et al. (2010) Biomechanical and histological outcome of combined raloxifene-estrogen therapy on skeletal and reproductive tissues. EurJ Pharmacol 627, 354-361.

15. Berrougui H, Grenier G, Loued S, et al. (2009) A new insight into resveratrol as an atheroprotective compound: inhibition of lipid peroxidation and enhancement of cholesterol efflux. Atherosclerosis 207, 420-427.

16. Danz ED, Skramsted J, Henry N, et al. (2009) Resveratrol prevents doxorubicin cardiotoxicity through mitochondrial stabilization and the Sirt1 pathway. Free Radic Biol Med 46, 1589-1597.

17. Fan GJ, Liu XD, Qian YP, et al. (2009) 4,4'-Dihydroxytrans-stilbene, a resveratrol analogue, exhibited enhanced antioxidant activity and cytotoxicity. Bioorg Med Chem 17, 2360-2365.

18. Dai Z, Li Y, Quarles LD, et al. (2007) Resveratrol enhances proliferation and osteoblastic differentiation in human mesenchymal stem cells via ER-dependent ERK1/2 activation. Phytomedicine 14, 806-814.

19. He X, Andersson G, Lindgren U, et al. (2010) Resveratrol prevents RANKL-induced osteoclast differentiation of murine osteoclast progenitor RAW 264.7 cells through inhibition of ROS production. Biochem Biophys Res Commun 401, 356-362

20. Faitel'son AV, Koklina N, Gudyrev OS, et al. (2012) [Comparative evaluation of the osteoprotective effects of resveratrol and resveratrol/enalapril combination in the treatment of experimental osteoporosis]. Eksp Klin Farmakol 75, 35-38

21. Tseng PC, Hou SM, Chen RJ, et al. (2011) Resveratrol promotes osteogenesis of human mesenchymal stem cells by upregulating RUNX2 gene expression via the SIRT1/ FOXO3A axis. J Bone Miner Res 26, 2552-2563.

22. Mizutani K, Ikeda K, Kawai Y, et al. (2000) Resveratrol attenuates ovariectomy-induced hypertension and bone loss in stroke-prone spontaneously hypertensive rats. $J$ Nutr Sci Vitaminol (Tokyo) 46, 78-83.

23. Su JL, Yang CY, Zhao M, et al. (2007) Forkhead proteins are critical for bone morphogenetic protein-2 regulation and anti-tumor activity of resveratrol. J Biol Chem 282, 19385-19398.

24. Liu ZP, Li WX, Yu B, et al. (2005) Effects of trans-resveratrol from Polygonum cuspidatum on bone loss using the ovariectomized rat model. J Med Food 8, 14-19.

25. Sehmisch S, Hammer F, Christoffel J, et al. (2008) Comparison of the phytohormones genistein, resveratrol and 8-prenylnaringenin as agents for preventing osteoporosis. Planta Med 74, 794-801.

26. Huang JH, Huang XH, Chen ZY, et al. (2004) Dose conversion among different animals and healthy volunteers in pharmacological study. Chin J Clin Pharmacol Ther 9, 1069-1072.

27. Food and Drug Administration (2002) Guidance for Industry and Review: Estimating the Safe Starting Dose in Clinical Trials for Therapeutics in Adult Healthy Volunteers. US Food and Drug Administration. http://www.fda.gov/cder/ guidance/index.htm

28. Ege CA, Parra NC \& Johnson TE (2006) Noninfectious complications due to vascular access ports (VAPs) in Yucatan minipigs (Sus scrofa domestica). I Am Assoc Lab Anim Sci 45, 27-34.

29. Mason S, Watts A, Sheils S, et al. (2007) Improving access to HCV treatment: external jugular venepuncture can overcome problems with difficult venous access. Int J Drug Policy 18, 433-436.

30. Terry CM, Kim SE, Li L, et al. (2009) Longitudinal assessment of hyperplasia using magnetic resonance imaging without contrast in a porcine arteriovenous graft model. Acad Radiol 16, 96-107.

31. Moon SJ, Ahn IE, Jung H, et al. (2013) Temporal differential effects of proinflammatory cytokines on osteoclastogenesis. Int J Mol Med 31, 769-777.

32. Tsuruoka S, Wakaumi M, Yamamoto H, et al. (2004) Chronopharmacology of oxacalcitriol in rat model of osteoporosis. Eur J Pharmacol 488, 239-245.

33. Zhang Y, Yu L, Ao M, et al. (2006) Effect of ethanol extract of Lepidium meyenii Walp. on osteoporosis in ovariectomized rat. J Ethnopharmacol 105, 274-279.

34. Xu Y, Han X \& Li Y (2010) Effect of marine collagen peptides on long bone development in growing rats. J Sci Food Agric 90, 1485-1491

35. Jing D, Shen G, Huang J, et al. (2010) Circadian rhythm affects the preventive role of pulsed electromagnetic fields on ovariectomy-induced osteoporosis in rats. Bone $\mathbf{4 6}$, $487-495$.

36. Hadjidakis DJ \& Androulakis II (2006) Bone remodeling. Ann N Y Acad Sci 1092, 385-396.

37. Huang QY, Li GH, Cheung WM, et al. (2008) Prediction of osteoporosis candidate genes by computational diseasegene identification strategy. J Hum Genet 53, 644-655.

38. Li YQ, Ji H, Shen Y, et al. (2009) Chronic treatment with angiotensin AT1 receptor antagonists reduced serum but not bone TGF-beta1 levels in ovariectomized rats. Can J Physiol Pharmacol 87, 51-55.

39. Mukherjee A, Dong SS, Clemens T, et al. (2005) Co-ordination of TGF-beta and FGF signaling pathways in bone organ cultures. Mech Dev 122, 557-571.

40. Rehn AP, Chalk AM \& Wendel M (2006) Differential regulation of osteoadherin (OSAD) by TGF-beta1 and BMP-2. Biochem Biophys Res Commun 349, 1057-1064.

41. Han X, Xu Y, Wang J, et al. (2009) Effects of cod bone gelatin on bone metabolism and bone microarchitecture in ovariectomized rats. Bone 44, 942-947.

42. Heymann MF, Riet A, Le Goff B, et al. (2008) OPG, RANK and RANK ligand expression in thyroid lesions. Regul Pept 148, 46-53

43. Deuell KA, Callegari A, Giachelli CM, et al. (2012) RANKL enhances macrophage paracrine pro-calcific activity in high phosphate-treated smooth muscle cells: dependence on IL-6 and TNF-alpha. $J$ Vasc Res 49, 510-521.

44. Pereda GO, Fudinaga AC, Beltran HS, et al. (2012) Inflammatory and bone regulators expression in murine macrophages under exposure of commercial and experimental mineral trioxide aggregate. Aust Dent J 57, 284-291.

45. Takahashi T, Tonami Y, Tachibana M, et al. (2012) Tetrandrine prevents bone loss in sciatic-neurectomized mice and inhibits receptor activator of nuclear factor kappaB ligandinduced osteoclast differentiation. Biol Pharm Bull 35, $1765-1774$. 